\title{
From Public Service Broadcasting to Soci(et)al TV
}

\author{
Producers' Perceptions of Interactivity \\ and Audience Participation in Finland and Israel
}

\author{
Heidi Keinonen \& Oranit Klein Shagrir
}

\begin{abstract}
In a changing media environment, television is being transformed by the adoption of practices such as audience participation and interactivity. This article analyses the ways in which managers and producers in Finnish and Israeli public service and hybrid television companies perceive participation and interactivity. We suggest that while these concepts can be described by hybrid broadcasters using the technologically- and commercially-oriented concept of 'social TV', the term does not adequately address the perceptions of socially-oriented public service broadcasters (PSBs). Hence, we propose the society- and value-oriented concept of 'soci(et)al TV' in an effort to conceptualise the PSBs' perceptions concerning the adoption of interactivity and participation practices while they seek to fulfil their social commitments and objectives. Our argument is based on a comparative study of two different broadcasting models (public service vs. hybrid) in two national media systems and cultures.
\end{abstract}

Keywords: television, public service broadcasting, interactivity, Finland, Israel, social TV

\section{Introduction}

The digitalisation of media technologies has resulted in changes to various levels of television culture. In addition to enabling technological convergence, digitisation has also brought about cultural transformations, such as the blurring of the traditional spheres of production and consumption. As a result, television companies - commercial broadcasters as well as public service broadcasters (PSBs) - are increasingly adopting multi-platform practices that enable interactivity and audience participation. Broadcasting company managers and producers face questions regarding the implications of these changes for television broadcasting, which is traditionally a form of one-to-many communication. Anxieties about the future of public service broadcasting have resulted in various speculations. One line of argument states that public service broadcasting is transforming into public service media (PSM) and extending public services beyond radio and television. These scholars argue that the Internet can be employed within a 
public service environment to involve and activate citizens socially, while ensuring that the core public service values of deliberation, reciprocity, and free and universal access are realised (van Dijck \& Poell 2014: 11 citing Coleman 2004; Lowe \& Bardoel 2007; Moe 2011; Murdock 2005). However, how this is perceived and implemented within broadcast television remains unclear.

In this article, we study the ways in which producers and managers in public service and hybrid television ${ }^{1}$ organisations perceive participation and interactivity in multiplatform entertainment and drama productions. Our main questions are: how are participation and interactivity perceived by public service and hybrid broadcasters, how and why should participation and interactivity be implemented, and how can participation and interactivity be combined with public service values and objectives.

We studied these questions in two specific media contexts within which broadcasters operate in two countries, Finland and Israel. We argued that hybrid television companies are primarily commercially oriented, and their understanding of participation and interactivity is revenue- and technologically-oriented. The existing concept of social TV, which refers to the integration of television and social media, is useful in describing the perceptions of hybrid company producers. However, PSB's perceptions of interactivity and participation focus on social values and public service objectives and are not defined by the concept of social TV. Thus, we propose a new concept, soci(et)al TV, to describe the perceptions of PSBs in Finland and Israel. With this new concept, our article contributes to the discussion concerning the possible implementation of interactivity and audience participation in television, particularly within public service broadcasting, by exploring two different broadcasting models, hybrid television and public service broadcasting, in two different cultural and media settings.

The article will begin with an overview of the television systems in the respective countries, the theoretical framework employed in the study, and the methodology of this article. Then, the findings concerning hybrid television companies and PSBs will be presented.

\section{Television systems in Finland and Israel}

Both Finland and Israel have dual broadcasting systems in which PSBs operate side by side with hybrid channels that have social and/or cultural responsibilities. This comparison enables us to reflect on the television managers' and producers' perceptions of their audiences and their audiences' participation within two national cultures and two media systems that have differences and similarities.

Israel and Finland are both rather small nations (Israel's population is approximately 8 million, and Finland is approximately 5 million). Both countries have relatively small broadcasting markets and unique languages (Hebrew in Israel and Finnish in Finland), which distinguishes them from their neighbouring countries and the rest of the world. However, Finland has maintained a substantially cohesive culture, while Israel is traditionally an immigrant society and is, therefore, multicultural and multilingual. Israel and Finland are regarded as high-technology countries. Finland gained this status primarily due to the success of Nokia mobile phones, but it was also the third country in the world to digitise terrestrial broadcasting in 2007. Israel has been dubbed a 'start-up nation' due to the numerous technological start-ups and innovations developed in the country ${ }^{2}$. 
These countries share a long tradition of public service broadcasting. However, the evolution of these institutions in Finland and Israel does not follow a similar pattern. Public service television in Israel has been in decline for some time now, while in Finland, it is still supported. The future of public service broadcasting in Finland was recently secured as the license fee was changed into a public broadcasting tax, which, however, raises questions of legitimacy. ${ }^{3}$ Israel's public service broadcasting future is unclear. Since the introduction of commercial television, the public channel has lost viewers to commercial channels due to many organisational difficulties, intensive political involvement, and a lack of effective management, which contributed to negative public sentiment towards public television in Israel, especially with regard to the obligatory license fee. Therefore, the Israeli government decided to dismantle the current malfunctioning public service agency and establish a new agency. ${ }^{4}$ The process is expected to take place in the near future. Therefore, PSBs in both Israel and Finland seek public legitimacy in completely different contexts.

In both countries, PSBs are supplemented with hybrid television companies. The hybrid model can be characterised as the integration of two basic broadcasting paradigms (i.e., public service and commercial broadcasting). A hybrid broadcaster is, by definition, commercially funded and usually dependent on advertising revenues. It is also constrained by explicit obligations and enjoys certain privileges (Hellman \& Keinonen 2013: 45-46). Finland was the first country in Europe to follow British Independent Television (ITV) in launching a hybrid television service, MTV, in 1958 (Hellman \& Keinonen 2013: 46). After operating for decades under the license of Yle, MTV finally received a broadcasting licence and channel of its own in 1993 (Hellman 1999: 169176). Another hybrid organisation, Nelonen (Channel Four), was launched in Finland in 1997. Both MTV and Nelonen are commercially funded, must apply for a broadcasting license, and have an obligation to broadcast news.

Israel also adopted the dual model, creating a mix of PSB and a free market approach, at the beginning of the 1990s (Lachman-Meser 1997). This hybrid structure of commercial broadcasting under public supervision is described as a suitable solution to public interest demands. As such, cultural programming is embedded in commercially oriented channels (Katz 2012). Israel has two commercially-funded national hybrid broadcast channels (channels 2 and 10) that are required to fulfil some of the obligations the public channel has failed to fulfil, including original drama productions, news and programming in Arabic, and programs that represent different segments of the population and Jewish heritage. The commercially oriented television companies in Israel are considered innovative ${ }^{5}$ as they develop new creative television formats that are exported globally. ${ }^{6}$

The media systems and nations of Israel and Finland share some notable similarities and a few striking differences, making them interesting case studies for comparative research. The channels that were studied are summarised in Table 1. 
Table 1. Channels studied

\begin{tabular}{|c|c|c|c|c|c|c|}
\hline \multicolumn{7}{|l|}{ Finland } \\
\hline Channel & Operator & Financing & $\begin{array}{l}\text { Programming } \\
\text { orientation }\end{array}$ & $\begin{array}{l}\text { Shares } \\
(2014) 7\end{array}$ & Obligations & Established \\
\hline 1 & $\begin{array}{l}\text { National } \\
\text { public service } \\
\text { broadcasting } \\
\text { company Yle }\end{array}$ & $\begin{array}{l}\text { Public broad- } \\
\text { casting tax }\end{array}$ & $\begin{array}{l}\text { Public ser- } \\
\text { vice, national }\end{array}$ & $26.4 \%$ & yes, legal & 1958 \\
\hline 2 & $\begin{array}{l}\text { National } \\
\text { public service } \\
\text { broadcasting } \\
\text { company Yle }\end{array}$ & $\begin{array}{l}\text { Public broad- } \\
\text { casting tax }\end{array}$ & $\begin{array}{l}\text { Public ser- } \\
\text { vice, national }\end{array}$ & $13.3 \%$ & yes, legal & 1965 \\
\hline 3 & $\begin{array}{l}\text { Private com- } \\
\text { pany: MTV }\end{array}$ & Advertising & $\begin{array}{l}\text { Hybrid, na- } \\
\text { tional }\end{array}$ & $17.4 \%$ & $\begin{array}{l}\text { yes, based } \\
\text { on broad- } \\
\text { casting } \\
\text { licence } \\
\end{array}$ & 1958 \\
\hline 4 & $\begin{array}{l}\text { Private } \\
\text { company: } \\
\text { Nelonen }\end{array}$ & Advertising & $\begin{array}{l}\text { Hybrid, na- } \\
\text { tional }\end{array}$ & $8.1 \%$ & $\begin{array}{l}\text { yes, based } \\
\text { on broad- } \\
\text { casting } \\
\text { licence } \\
\end{array}$ & 1997 \\
\hline \multicolumn{7}{|l|}{ Israel } \\
\hline Channel & Operator & Financing & $\begin{array}{l}\text { Programming } \\
\text { orientation }\end{array}$ & $\begin{array}{c}\text { Share } \\
(2014) 8\end{array}$ & Obligations & Established \\
\hline 1 & $\begin{array}{l}\text { Israeli } \\
\text { Broadcasting } \\
\text { Authority }\end{array}$ & Licence fee & \begin{tabular}{|l|} 
Public \\
Broadcasting \\
National \\
\end{tabular} & $7.1 \%$ & yes, legal & 1968 \\
\hline 2 & $\begin{array}{l}\text { Private com- } \\
\text { panies: Kes- } \\
\text { het, Reshet } \\
\text { (broadcasting } \\
\text { on alternate } \\
\text { days) }\end{array}$ & Advertising & $\begin{array}{l}\text { Commercial, } \\
\text { Hybrid, Na- } \\
\text { tional }\end{array}$ & $35.4 \%$ & $\begin{array}{l}\text { yes, based } \\
\text { on charter } \\
\text { conditions }\end{array}$ & 1993 \\
\hline 10 & $\begin{array}{l}\text { Private com- } \\
\text { pany: Israel } \\
10\end{array}$ & Advertising & $\begin{array}{l}\text { Commercial, } \\
\text { Hybrid, Na- } \\
\text { tional }\end{array}$ & $14.3 \%$ & $\begin{array}{l}\text { yes, based } \\
\text { on license } \\
\text { conditions }\end{array}$ & 2002 \\
\hline
\end{tabular}

\section{Theoretical framework: participation, interactivity, and social TV}

In this section, we will discuss three central concepts relating to current television audiences: participation, interactivity, and social TV. Without revisiting all the theories attributed to participation and interactivity, we will briefly identify some academic definitions of these occasionally overlapping concepts.

Audience participation has a variety of meanings (García-Avilés 2012: 430). Carpentier (2011: 67) states that the term participation in a media context usually refers to two interrelated forms of participatory action: participation through the media and participation in the media. Participation through the media refers to mediated participation in public debate and opportunities for self-representation in a variety of public spaces. Historically, involving people in social and political issues has been an important ideological tenet in both public television and the so-called media democratisation movements (Enli \& Syvertsen 2007: 154). New information and communication technologies led many writers to renew their hopes for the media's potential to involve people in 
social and political issues (Enli \& Syvertsen 2007: 155). But whether this potential has been fully materialized is debatable (Stromer-Galley 2004), as the example of public service broadcasting demonstrates.

While participation through media has been a central objective for PSBs, they have been reluctant to embrace some forms of public participation (Enli 2008: 107; Enli \& Syvertsen 2007: 155). Some scholars even argue that PSBs have largely failed to respond to the rise of a networked society (Jakubowicz 2010: 16) and find it challenging to create platforms where interaction can take place (Lowe 2008: 16). Currently, participation is considered a strategic response to the challenges of the digital age by the commercial media industry as well as by PSB organizations. While the British BBC, the Swedish SVT, the Norwegian NRK, and the U.S.'s PBS all emphasise audience participation, they represent a new turn in public service broadcasting (Enli 2008: 109). The leaders in the commercial television industry believe that participation encourages viewers' loyalty through innovation and branding, which eventually increases revenues (Maasø et al. 2012). These assumptions increased our interest in whether and how managers and producers want viewers to participate and/or interact since only they can extend the invitation.

Participation in the media includes participation in the production of media output and in media organisation's decision-making process (Carpentier 2011: 67). Puijk (2015) identifies various forms of participation in the production of media output, such as participating in the programme itself, direct interaction with the programme production team, and participation through social media. Therefore, in a very limited sense, participation includes feedback opportunities which the broadcasters provide through a combination of traditional systems and new technologies, such as voting by SMS for a particular candidate on a reality show or calling to give one's opinion on a talk show (García-Avilés 2012: 430).

The typology of participation mentioned in Carpentier's article (2011: 70) summarizes the various definitions available: 1) participation in media production, 2) participation in society through the media, and 3 ) interaction with media content. This typology proved useful in structuring our findings while addressing the differences between hybrid television and public service broadcasting in the two countries. It also helped us to address the relationship of participation and interactivity, as the last category, interaction with media content, comes close to the definition of interactivity. While several scholars offer definitions and typologies of interactivity (e.g., Carpentier 2007; Askwith 2007; Jensen 1999; Steuer 1992), most of these typologies are technology- and interaction-oriented and describe technological affordance and audiences' ability to interact and impact media texts. Even though the academic discourse makes a distinction between the two concepts of participation and interactivity, it is apparent that certain facets of these concepts overlap. Furthermore, we have later discovered that the professional discourse of our interviewees often finds these two concepts interchangeable.

While participation and interactivity both refer to various forms of audience activity, new concepts emerge to describe the nascent forms of media. 'Social TV' is concerned with creating a buzz, especially in the U.S. media industry, but the concept is only beginning to emerge in European media organisations and academic research on broadcasting and convergence. Social TV is derived from 'social media + TV'. Television audiences use social media to engage with other viewers; they use mobile apps to vote, play, and expand their experience while seeking and sharing information before, during, and after 
they watch a television programme (see Marinelli \& Andò 2014: 25). These features are supported by a number of social media systems and applications (see Harboe 2009). Selva (2016: 161) defines social TV as a combination of technological and cultural points of view. The former refers to technological media innovation developments, while the latter highlights social practices, such as sharing, commenting, and networking. One example of these practices is a dialogue between the producers and the viewers (Enli 2012). Although social TV is still in its early stages, it is changing commercial broadcasting and has a visible impact on its public counterpart (van Dijck \& Poell 2014: 2). What this impact is and how commercially- and technologically-oriented social TV could be adapted to public service television has not yet been studied.

Using these three widely discussed concepts as a starting point, we sought to explore the producers' ideas on audience participation and contribute to the understanding of the transformation from public service broadcasting to PSM.

\section{Methodology}

We conducted a comparative study on two levels, PSBs and hybrid organisations as well as Finland and Israel. Comparative research should always be system-sensitive and seek to understand how the systemic context may have shaped the phenomena in question (Blumler et al. 1992: 7).

Our study focused on analysing television producers and managers' perceptions of interactivity and participation in the context of national broadcasting systems and institutions. Comparative research forces scholars to develop theoretical explanations that can be applied across social systems (Dutton \& Vedel 1992: 87). Thus, we sought to develop a new concept to describe social TV in the context of PSBs, soci(et)al TV. Our study is also sensitive of temporal changes - not through historical comparisons between Finnish and Israeli media systems but through awareness that 'system features and patterns are not eternal but instead are in continual flux' (Blumler et al. 1992: 9).

Constant change is characteristic of the media systems in Finland and Israel as the future of public service broadcasting is in transition and is still unclear in Israel. All meaningful comparisons require comparable objects, and although Finland and Israel are somewhat different in terms of culture and current media systems, they share many characteristics. The principal argument for the comparative research in this case lies in the broadcasting histories of the two relatively small countries. They both adopted PSBs along with hybrid broadcasting channels.

We conducted semi-structured interviews with managers and producers in PSB companies and hybrid television companies in Finland and Israel. Five interviews were conducted at the Israeli public television channel (IBA channel 1); five interviews at two broadcasting companies (Keshet and Reshet), which jointly operate Israel's most popular broadcast channel (channel 2); and four interviews at private production companies working with the two hybrid channels ${ }^{9}$ (channels 2 and 10). In Finland, four interviews were conducted at Yle (television channels Yle TV1 and Yle TV2) and two interviews were conducted at each hybrid organisation, MTV and Nelonen, for a total of four hybrid organisation interviews. The interviews were conducted from December 2013 to March 2014 in the respective national languages (Hebrew in Israel and Finnish in Finland). The interviewees from both countries were chosen based on their involve- 
ment in entertainment and drama productions as well as their ability to influence the production norms of the organisation. The interviews focused on television managers' and producers' perceptions of multi-platform practices, interactivity, and participation as well as audience expectations. The interviews included questions such as: do you think the roles of viewers are changing, do you think viewers are becoming co-creators of television texts, do viewers have more impact on television texts today, and what kind of involvement do multi-platform productions enable. The wording of our questions was intentionally general so the interviewees used their own terms to discuss their perceptions of concepts like interactivity and participation.

The interviews were transcribed and analysed to identify the producers' main perceptions of audience participation. Initial analyses were conducted separately in each country. The results of the separate analyses were compared, combined, and analysed further. As the interviewees in Israel insisted on full anonymity, we have anonymised all our interviewees ${ }^{10}$. Therefore, in this article, we refer to the interviewees using the abbreviations F1, F2, etc. for Finnish interviewees and IS1, IS2, etc. for Israeli interviewees.

\section{Producers' perceptions of changing audiences}

Due to the overall commercialisation of the television market, audience ratings and preferences increasingly direct the programming in both PSB companies and their commercial rivals. However, viewers have become more fragmented, more active, more mobile, and thus, more difficult to reach. We found that producers in both countries perceive that their television audiences are going through fundamental viewing preference and consumption pattern changes. In the Finnish public broadcasting company Yle, audience research is conducted on various platforms (F1), such as broadcast television, streaming services and social media, to gather information on what the viewers really want (F4). Audiences are seen as more active than before, and they want to use multiple platforms (F1, F2), consume transmedial content (F1), and have the opportunity to 'comment, share [and] forward information if they think it is interesting' (F3). Viewers split their time between multiple screens, sometimes simultaneously (F5, F6), and at least, the younger members of the audience are perceived to expect multi-platform content and a chance to interact, discuss, and participate (F5, F6, F7).

The interviewees in Israel stated that they were aware of the viewers' changing preferences: 'Today everyone concentrates on these small screens. This is the language of the $21^{\text {st }}$ century' (IS2). They emphasised the perceived impact of technology on television viewers: 'Technology changed them. They want to be active. They want more options' (IS1). One interviewee elaborated on the nature of activity and stated, 'In the past, people would watch TV at night, go to sleep, and talk about their experience the next morning at work. Today, they want to discuss what they watch as they watch it. I can see it all the time' (IS10). Viewers are also perceived as active and even interactive: '...[viewers] used to be "couch-potatoes", not any more. They are very interactive; they want to be heard and seen. For example, if a viewer's post is read on TV, it is like giving him a prize...everyone wants to participate and then tell all their friends about it' (IS11). These findings are consistent with previous research (Enli 2008; Sundent \& Ytreberg 2009) that shows that producers strongly believe their viewers expect to interact with media texts. 
Producers had a two-fold perception of the viewers in both countries. They described their audiences as eager to actively participate, but they believed that their viewers valued television for the information and 'good stories' it shares and they valued the opportunity to watch passively. In Finland, the managers and producers at hybrid companies believed that television still gathers together families and large audiences who search for common experiences and touching stories (F5, F6, F7, F8). One interviewee stated, 'scheduled TV will not end [because] viewers expect easiness [...] I think that many people just want to see what is on, lay on the coach, and switch channels also in the future' (F8). In Israel, people gather around broadcast television channels for information during national events, such as wars or elections. ${ }^{11}$

To conclude, interviewees in both countries described changes in where and how audiences consume television content. They seemed to agree that the audiences increasingly expect to be active and interact and participate on multiple platforms. However, while digital media may enable participation and interactivity, television is traditionally a broadcast medium, and viewers are not usually able to produce or distribute their messages on television (see Ellis 2004: 276). The study interviewees admitted that television must adapt to viewers' changing expectations, and both the PSBs and hybrid companies sought to meet their audiences' participation and interactivity expectations. However, these companies had different understandings of how this should be done. The following sections will explore the different understandings of the purpose and implementation of these concepts. First, we will review hybrid companies' perceptions, and then, we will focus on PSB organisations.

\section{Participation and interactivity in hybrid television companies: creating the buzz}

To understand the context in which PSBs operate, it is essential to consider hybrid companies' perceptions of participation and interactivity. Uncovering hybrid companies' perceptions will allow us to identify PSB's unique definitions of participation and interactivity in relation to its social role.

While conducting the interviews, we realised that the managers and producers of the broadcasting companies in both countries lacked a common understanding of the meaning of participation and interactivity, which is why we allowed our interviewees to determine which terms to use to describe these issues. Concepts like interactivity, activity, interaction, participation, and influence were used to refer to the ways in which audiences interact with the media texts, production process, and other members of the audience. In the Finnish hybrid companies, interactivity mainly included activities such as voting, polls, competitions, game-like activities, and commenting on televisual content (F5, F7, F8). Emphasising their commercial orientation they describe interactivity as an opportunity 'to engage in the program and, possibly also, in the associated brands' (F8). The Finnish interviewees also commented that interactivity is nothing new; viewers have voted throughout the history of television through calling to the studio or sending postcards (F7, F8; also Keinonen 2011: 148-149; Beyer et al. 2007; Enli 2012: 126). Multi-platform productions only provide television with new forms of interactivity (F8) as the one-to-many medium is accompanied by other many-to-many mediums. Consequently, interactivity may also refer to the ability to share the viewing experience with other audience members (F6). 
Two slightly different understandings of interactivity and participation existed within the Israeli interviewee group. One group defined these activities as those that accompany televisual content, such as providing the viewers with an opportunity to discuss television content on social media, whereas another group defined viewers' participation or interactivity as a core element of a program. One of the interviewees stated, '...people want to talk about what they watch while they watch, and we have to accommodate it' (IS10). However, most interviewees stated that they want the viewers to discuss linear broadcasts both with their friends in front of the TV set and on social media.

A few interviewees also believed that interactivity and participation are integral parts of the media text. For example, as a part of an original format called Rising Star, Keshet developed a specialised app that allowed viewers to participate throughout the program. Much time and funding were invested in the development of the technological platform that allowed viewers to vote for the contestants in real time (IS10, IS9, IS12). Commercially-oriented Israeli hybrid channel producers stated that participation and interactivity through digital platforms is almost unavoidable since it can increase the buzz around various programs and draw more viewers (IS6, IS7).

While the interviewees in Israel and Finland seemed to share an understanding of the implementation and purpose of interactivity and participation, differences in their understandings were also found. Israeli interviewees had rather enthusiastic attitudes while the interviewees from the Finnish hybrid companies were somewhat hesitant about interactivity and participation. Although interactivity was recognised as a central feature in multi-platform productions, some of the Finnish interviewees were sceptical about these productions. They described interactivity as 'superficial' (F5) and 'overrated' (F7) and more para-interactivity than interactivity. (Para-interactivity refers to the features or elements of broadcast television that echo interactive communication processes and are characteristic of digital media and participatory culture, but do not typically create interactive communication (Klein-Shagrir 2015: 2-4)).

The idea that viewers become co-producers, consumers become prosumers, and professional media content is replaced by user-generated content (UGC) was rejected by the interviewees from both Finnish hybrid companies (F5, F6, F8). One of the interviewees stated, 'I believe that if the best [screenwriting] man in Finland is telling the story, it will be better than if we sit down together and think about how the storyline develops' (F8).

The hybrid company managers and producers in both countries discussed interactivity and participation through a commercial lens. They stated that audience participation included voting, gaming, and sharing and commenting on television programs. Thus both the Finnish and Israeli interviewees described participation as interaction with media content.

The other elements of participation (participation in media production and participation in society through media) defined by Carpentier (2011) were explicitly rejected by the interviewees. As the interviewees were unconcerned with extending audience engagement beyond the actual program content, their objectives regarding participation and interactivity were mainly commercial. Thus, social TV is mainly produced by commercial broadcasters who focus their efforts on creating buzz about their content. Hybrid companies' perceptions become even more distinct when they are compared to PSBs' ideas about audience participation and interactivity. 


\section{'We should do it differently' - from public service broadcasting to soci(et)al TV}

Interviewees in both countries consistently shared the notion that interactivity and viewer participation should be employed by PSB organisations in different ways and for different purposes than in hybrid TV companies. The Israeli interviewees declared their commitment to their audiences and believed that they should offer different content than that provided by commercial channels (IS5). 'We must not be just like the commercial channels; we should do things differently even though the competition is fierce' (IS2). These interviewees emphasised that their 'public mandate is not commercial' (IS1) and proclaimed their willingness to receive lower ratings than the commercially oriented channels. 'We have to present an alternative to commercial channels even if we lose in the ratings' (IS5). The PSB interviewees even suggested that some popular multi-platform productions with interactive features should not be produced by public television at all. Instead, these productions should be left to commercial television (IS5) as PSBs must 'keep the cultural standards' (IS2).

At Yle, interactivity was perceived differently than the commercial connotation of providing the audience with a chance to vote (F2). Finnish managers saw interactivity as a way to activate the audience in ways that are not possible in broadcast television (F1). PSBs in both countries believed that they should enable viewer participation and interactivity in ways that meet their objectives; however, each suggested slightly different strategies for realising these objectives. The interviewees at Yle highlighted two main aims: to increase interaction between the audience and the production team and to encourage interaction between the audience and the surrounding society, for wider social issues. These aims correlate with the two elements of participation: participation in media production and participation in society (Carpentier 2011). The interviewees stated that the first aim can be achieved by providing the viewers with opportunities to participate in live broadcast through Twitter feeds (F4), which will allow the viewers to communicate with the production team (F4) and suggest ideas and guests the production team should include on the program (F2, F3). One of the interviewees stated, 'The production team comes close to you [...] that's the thing' (F2). Multi-platform productions may enable more advanced forms of interaction than, for example, the SMS-based television shows that only provide viewers with limited partial or dominant influence on the television text (Beyer et al. 2007: 228-229), but do not enable interaction between production and the audience beyond the actual television program. By opening productions and making them transparent to both the audience and commercial competitors, ${ }^{12}$ Yle gives something in return for the broadcasting tax individuals and companies pay (F4).

Yle also attempts to motivate its viewers to engage in social issues by providing them with extra information, such as links to NGO websites and space for their own stories (F1). Debrett (2009) states that PSB portal websites' always-on interfaces offer spaces in which diverse audiences and/or user groups are exposed to a wide range of ideas, services, and communities. In accordance with the PSB values, huge amounts of background material for radio and television programmes are displayed on these websites, allowing the producers to engage in a wide range of social issues in a very different manner than the distinctly promotional websites of commercial television (Debrett 2009: 816, 818). For example, Yle invites viewers to participate through the Yle FOLK service, which is designed to gather content from contributors around the country and 
make it available on the Yle's website and radio and TV outlets. Yle is 'on the lookout for the next generation of comedians, investigative journalists, and Internet sensations', and its goal is to make its regional coverage more current. ${ }^{13}$

While the interviewees in Finland were concerned about the legitimacy of Yle, they had a flexible and innovative attitude towards PSB functions and objectives, including the transparency of Yle's work processes, its goal to encourage its audiences' involvement in social issues, and the actual participation of its viewers in producing media content and becoming performers. Interviewees in Israel expressed a slightly more conservative attitude towards the realisation of these values through interactivity and participation. These interviewees claimed that they used social media to 'include the public' (IS3) and 'hear the public' (IS4), and they believed that viewers' opinions and preferences concerning television content should be taken into account (IS2, IS4). An IBA manager stated, 'I would like to make the viewers partners in the production from the beginning to the end...' (IS1), which is very similar to statements made by Finnish producers. Another stated, 'as a PSB, it is our number one priority to share things with our public to make them a part of our activities' (IS3). IBA's strategy involves 'letting the public express itself in the public sphere...this is our commitment as a public authority...' (IS1). One interviewee revealed, 'We encourage public engagement, for example, by allowing the audience to express themselves on Facebook, and we even show it onscreen, after selection and editing, obviously...' (IS2), while another stated, 'we want different social groups and minorities to have access to the media so we hear their voices...' (IS5). In addition, IBA managers wanted to offer online content in Arabic or content for Ethiopian immigrants in Israel. IBA interviewees also believed they should integrate interactivity for educational and cultural preservation purposes, which is a PSB objective. One interviewee explained, 'interactivity can be included in content such as science, classical music...for example, viewers can learn about the human body on-line...' (IS1). Other interviewees revealed that enabling public access to IBA's audio-visual archives through digital platforms is another significant PSB objective (IS1, IS2, IS4).

These quotes show that PSB's perceptions of interactivity and participation in both countries are related to public service values, such as inclusion of the public, encouraging involvement in social issues, education, cultural preservation, and the representation of various social groups and minorities. While the focus on and ways in which these strategies are implemented differ between the two countries, all these objectives are far removed from the purposes of interactivity and participation noted by hybrid companies' producers, namely, 'creating a buzz' and enhancing ratings.

These findings established that PSBs consider interactivity and participation as a way to move from broadcast television to soci(et)al TV. While other scholars focus on social media and its employment by television companies, discussing their findings in the context of social TV, we adopted a wider, value-oriented approach through which we explored PSB's perceptions of multi-platform adoption. PSBs believe that public television in a multi-platform environment can be more than mere technologies/ platforms or social TV. Our interviewees strived to establish a more social television service through the employment of social media (see van Dijck \& Poell 2014) or by encouraging social interaction in the limited context of television text (Enli 2012). However, the interviewees mainly sought to produce socially-oriented television similar to traditional PSBs (see also Klein-Shagrir \& Keinonen 2014). The adoption of social 
media within PSBs should differ from that of commercial or hybrid broadcasters and include social objectives, such as providing citizens with information, education, and content through archival access while offering them platforms for interaction with the content, the producers, and each other.

This kind of television is socially oriented on two levels: first and foremost, through the realisation of social objectives and second, by becoming socially networked on digital platforms. We proposed the new concept of soci(et)al TV to examine PSB's perceptions and intentions in a digital environment since this concept integrates the objectives and values of PSBs to social TV.

\section{Conclusions}

In this article, we analysed the perceptions of participation and interactivity in PSBs and hybrid television companies in Finland and Israel. We conducted a comparative study on two levels by including two different models of broadcasting (public service and hybrid) as well as two national media settings and cultures. We found a few differences between the two countries, but there were many more similarities, which may allow our findings to be generalised for PSB organisations in other places.

Interviewees from both PSBs and hybrid companies admitted that viewers have changed and that they saw a need to offer some kind of audience participation capability. However, managers and producers in Finnish hybrid companies were more sceptical of interactivity and participation than their colleagues in Israel. While the Finnish interviewees did not believe in user-generated content and viewed voting and polls as interactivity, the hybrid companies in Israel invested large amounts of time and funds into developing innovative interactive digital platforms. Despite having social obligations as part of their broadcasting conditions, the hybrid companies in both countries were commercially orientated and saw interactivity and participation as a way to generate ratings, revenues, and buzz, which can be described as social TV practices.

PSBs in both countries declared their commitment to PSB objectives and believed they should find appropriate ways to use audience participation and interactivity to best realise their social orientation. Although multi-platform productions may encounter challenges (Klein-Shagrir \& Keinonen 2015), they enable new forms of participation and interactivity.

PSBs in Finland and Israel operated under completely different circumstances and constraints, but they both sought to differentiate themselves from commercial channels. Yle emphasised openness and accessibility and did not consider voting and polls as the kind of participation PSB should enable. Instead, Yle believed it should enable interaction with the PSBs and their production teams and among the Finnish society and its members. IBA interviewees believed that interactivity and participation through additional platforms should be allowed. In addition, they claimed that the public should be allowed to access IBA's archives to learn about Israel's history and heritage for educational and cultural purposes, or they should be used to invite peripheral groups to express themselves in public.

By analysing two case studies in different cultural and media settings, we learned that while social TV fits hybrid companies' perceptions of participation and interactivity, it does not do justice to socially-oriented PSBs. We found that PSB producers' and man- 
agers' perceptions of audience participation and interactivity are oriented towards their commitment to traditional PSB objectives, which are best described using the concept of soci(et)al TV. Soci(et)al TV is a society- and value-oriented version of the technology- and commercially-focused social TV. Therefore, soci(et)al TV has a double-layered meaning that addresses PSB's efforts to adopt digital platforms while realising their social commitments and objectives.

One might argue that adopting participation and interactivity is merely a strategic measure in times of uncertainty. However, we found that even as a strategy, the ways in which producers in PSB organisations articulated their perceptions of these concepts, which were different from hybrid organisations, highlight their commitment to PSB values. This perceived commitment is significant in light of the concerns that PSBs may sacrifice their values when strategic managers embrace market-based perspectives (Palokangas \& Lowe 2010: 135). Therefore, further research should explore the strategy and policy documents of PSBs as well as the actual manifestations of soci(et) al TV in PSB media content. Although each PSB organisation adopts different public service objectives, we propose that the concept of soci(et)al TV captures the essence of this unique definition of participation and interactivity. Furthermore, soci(et)al TV can serve as a normative foothold for PSB organisations in the digital media environment.

\section{Notes}

1. Throughout this article, 'hybrid' refers to hybrid television companies, i.e., those that combine public obligations with commercial funding.

2. http://startupnationbook.com/

3. http://Yle.fi/Yleisradio/about-Yle/financing

4. http://www.the7eye.org.i1/100086

5. http://www.haaretz.com/print-edition/features/can-israeli-tv-shows-go-the-way-of-high-tech-1.367987

6. http://www.haaretz.com/business/israeli-tv-shows-are-already-a-hit-abroad-but-producers-believe-thesky-s-the-limit.premium-1.514654

7. http://www.finnpanel.fi/tulokset/tv/vuosi/share/2014/

8. http://www.ynet.co.il/articles/0,7340,L-4611055,00.html

9. Since access to its employees was limited, the Israeli interviews were included in the Israeli context to explain the Channel 10 production processes.

10. Israeli PSB interviewees insisted on anonymity due to the situation within the organisation for which they work. The Israeli PSB is on the verge of being dismantled, and its employees' futures are unknown. As a result, they were unsure whether they were allowed to be interviewed and were hesitant to ask for permission. They were also reluctant to risk their future employment prospects by providing comments that criticised their employers. Israeli commercial broadcaster employees insisted on anonymity since most of them had signed confidentiality agreements. From a methodological point of view, allowing them anonymity protected them while it encouraged them to speak more freely.

11. During election night (17 March, 2015), almost 70 per cent of Israelis watched the three main broadcast channels. http://b.walla.co.il/item/2838769 (accessed 8 July, 2015).

12. For example, people from the hybrid broadcaster Nelonen have visited a multi-platform drama production Uusi päivä at Yle (F4).

13. http://yle.fi/uutiset/yle_launches_new_folk_service_for_sharing_media_content_contributions_welcome/8231508(accessed 7 October, 2015)

\section{References}

Askwith, Ivan (2007). Television 2.0: Reconceptualising Television as an Engagement Medium. Master's Thesis, Massachusetts Institute of Technology.

Beyer, Yngvil; Enli, Gunn Sara; Maasø, Arnt Johan, \& Ytreberg, Espen (2007). Small Talk Makes a Big Difference: Recent Developments in Interactive, SMS-Based Television. Television \& New Media, 8(3): 213-234. 
Blumler, Jay G.; McLeod, Jack M., \& Rosengren, Karl Erik (1992). An Introduction to comparative communication research, pp. 3-18 in Blumler, Jay G.; McLeod, Jack M., \& Rosengren, Karl Erik (eds.) Comparatively Speaking: Communication and Culture Across Space and Time. Park, London \& New Delhi: Sage Publications.

Carpentier, Nico (2007). Participation, Access and Interaction: Changing Perspectives, pp. 214-230 in Nightingale, Virginia, \& Dwyer, Tom (eds.) New Media Worlds. Challenges for Convergence. Oxford: Oxford University Press.

Carpentier, Nico (2011) Media and participation. A site of ideological-democratic struggle. Bristol (UK): Intellect.

Debrett, Mary (2009). Riding the wave: public service television in the multi-platform era. Media, Culture \& Society, 31(5): 807-827.

Dutton, William H. \& Vedel, Thierry (1992). The Dynamics of Cable Television in the United States, Britain and France, pp. 70-93 in Blumler, Jay G.; McLeod, Jack M., \& Rosengren, Karl Erik (eds.) Comparatively Speaking: Communication and Culture Across Space and Time. Park, London\& New Delhi: Sage Publications.

Ellis, John (2004). Television production, pp. 275-292 in Allen, Robert C., \& Hill, Annette (eds.) The Television Studies Reader. London \& New York: Routledge.

Enli, Gunn Sara (2008). Redefining Public Service Broadcasting: Multi-Platform Participation. Convergence, 14(1): 105-120.

Enli, Gunn Sara (2012). From parasocial interaction to social TV: Analysing the host-audience relationship in multi-platform productions. Northern Lights, 10: 123-137.

Enli, Gunn, \& Syvertsen, Trine (2007). Participation, Play and Socialising in New Media Environments, pp. 147-162 in Nightingale, Virginia, \& Dwyer, Tom (eds.) New Media Worlds. Challenges for Convergence. Oxford: Oxford University Press.

García-Avilés, José Alberto (2012). Roles of audience participation in multiplatform television: From fans and consumers, to collaborators and activists. Participations, 9(2): 429-447. Available at: http://www. participations.org/Volume\%209/Issue\%202/24\%20Garcia-Aviles.pdf (accessed 1 October, 2015).

Harboe, Gunnar (2009). In search of social television, pp. 1-12 in Cesar, Pablo; Geerts, David, \& Chorianopoulos, Konstantinos (eds.) Social Interactive Television: Immersive Shared Experiences and Perspectives. Hershey \& New York: Information Science Reference.

Hellman, Heikki (1999). From Companions to Competitors. The Changing Broadcasting Markets and Television Programming in Finland. Tampere: Tampere University Press

Hellman, Heikki, \& Keinonen, Heidi (2013). Semi-commercial or semi-public service? Legitimacy and regulation of commercial television in Finland. Comunicazioni Sociali 2013(3): 44-57.

Jakubowicz, Karol (2010). PSB 3.0: Reinventing European PSB, pp. 9-22 in Iosofidis, Petros (ed.) Reinventing Public Service Communication. European Broadcasters and Beyond. Basingstoke (UK): Palgrave MacMillan.

Jensen, Jens F. (1999). Interactivity: Tracing a new concept in media and communication studies. Nordicom Review, 12(2): 185-204.

Katz, Yaron (2012). Media Policy in Israel: The New Structure of Public Broadcasting. Journalism \& Mass Communication, 2(5): 581-596.

Keinonen, Heidi (2011). Kamppailu yleistelevisiosta. TES-TV:n, Mainos-TV:n ja Tesvision merkitykset suomalaisessa televisiokulttuurissa 1956-1964. Tampere: Tampere University Press.

Klein-Shagrir, Oranit, \& Keinonen, Heidi (2014). Public service television in a multi-platform environment: A comparative study in Finland and Israel. VIEW Journal of European Television History \& Culture, 3(6): 14-23. http://www.viewjournal.eu/index.php/view/article/view/JETHC066/162

Lachman-Meser, Davida (1997). The new communications map in Israel: Explanation of a process, characteristics, and regret. Dvarim Achadim, 1: 66-87.

Lowe, Gregory Ferrell (2008). Customer Differentiation and Interaction: Two CRM Challenges for Public Service Broadcasters. Journal of Media Business Studies, 5(2): 1-22.

Lowe, Gregory Ferrell, \& Bardoel, Jo (2007). From Public Service Broadcasting to Public Service Media: the core challenge, pp. 9-26 in Lowe, Gregory Ferrell, \& Bardoel, Jo (eds.) From Public Service Broadcasting to Public Service Media. Göteborg: Nordicom, Göteborgs Universitet.

Maasø, Arnt; Sundet, Vilde Schanke, \& Syvertsen, Trine (2012).Because They Deserve It: Audience Participation as a Strategic Development Area in the Media Industry, in Sundet, Vilde Schanke, Making Sense of Mobile Media: Institutional Working Notions, Strategies and Actions in Convergent Media Markets. Master's Thesis, Oslo: University of Oslo.

Marinelli, Alberto, \& Andó, Romana (2014). Multi-screening and social TV: The changing landscape of TV consumption in Italy. VIEW - Journal of European Television History and Culture, 3(6): 24-36. Available at: http://viewjournal.eu/index.php/view/article/view/JETHC067/164 (accessed 1 October, 2015). 
Moe, Hallvard (2011). Defining public service beyond broadcasting: the legitimacy of different approaches, International Journal of Cultural Policy, 17(1): 52-68

Murdock, Graham (2005). Public broadcasting and democratic culture: Consumers, citizens, and communards, pp. 174-198 in Wasko, Janet (ed.) A companion to television. Malden (USA): Wiley-Blackwell.

Palokangas, Teemu, \& Lowe, Gregory Ferrell (2010). Heritage Brand Management in Public Service Broadcasting, pp. 128-141 in Iosifidis, Petros (ed.) Reinventing Public Service Communication. European Broadcasters and Beyond. Basingstoke (UK): Palgrave MacMillan.

Puijk, Roel (2015). Slow Television. Nordicom Review, 36(1): 95-108.

Selva, Donatella (2016). Social Television: Audience and Political Engagement. Television and New Media, 17(2): 159-173.

Shagrir, Oranit Klein (2015). Unveiling television's apparatus on screen as a 'para-interactive'strategy. Media, Culture \& Society, 37(5): 737-752.

Steuer, Jonathan (1992). Defining virtual reality: Dimensions determining telepresence. Journal of Communication, 42(4): 73-93.

Stromer-Galley, Jennifer (2004). Interactivity-as-product and interactivity-as-process. The Information Society, 20(5): 391-394.

Sundet, Vilde Schanke, \& Yrteberg, Espen (2009). Working notions of active audiences: Further research on the active participant in convergent media industries. Convergence, 15(4): 383-390.

Van Dijck, José, \& Poell, Thomas (2014). Making Public Television Social? Public Service Broadcasting and the Challenges of Social Media. Television and New Media, 16(2): 148-164.

HEIDI KEINONEN, D.Soc.Sc., Post-Doctoral Researcher, Turku Institute for Advanced

Studies, University of Turku, heidi.keinonen@utu.fi

ORANIT KLEIN SHAGRIR, Ph.D., Senior Lecturer, Hadassah Academic College and Open University of Israel, oranit@hadassah.ac.il 